\title{
Um projeto de educação para a criança no século XIII: considerações acerca da pedagogia de Ramon Llull
}

\section{A project of education for the child in the thirteenth century: considerations of the pedagogy of Ramon Llull}

\author{
Conceição Solange Bution Perin* \\ Terezinha Oliveira* ${ }^{* *}$
}

\begin{abstract}
RESUMO
Este estudo analisa a proposta de educação para a criança apresentada na obra Doctrina Pueril de Ramon Llull (1232-1316). A obra foi escrita para seu filho, Domingos, por volta do ano de 1275-1276. Consideramos as reflexões e, especialmente, as regras propostas por Llull como essenciais para a formação humana. Segundo o autor, o desenvolvimento humano não é algo que se adquire naturalmente, pois demanda ensinamentos, modelos e exemplos a partir dos quais as crianças apreendem e seguem desde a mais tenra idade. Centraremos a análise nos princípios educacionais que Llull ensinou a seu filho acerca das virtudes e crenças necessárias para a formação da pessoa. Do ponto de vista do autor, esses conhecimentos deveriam ser norteados por meio das ciências, por conseguinte, segundo princípios da racionalidade. Para elaborarmos nossa análise sobre a proposta de Llull retomaremos, também, outros intelectuais da Idade Média, como Hugo de São Vitor (1096-1141), Boaventura de Bagnoregio (1221-1274), dentre outros. Nesse sentido, entendendo ser a educação uma exigência atemporal. O estudo tem como pressuposto metodológico a História de Longa Duração, pela qual podemos, de acordo com Marc Bloch (1886-1944), entender o homem como 'fundo permanente' de qualquer momento histórico.
\end{abstract}

Palavras-chave: Ramon Llull. Intelectuais. Ensino/Pedagogia. Criança.

* Universidade Estadual do Paraná. Campus de Paranavaí. Paranavaí, Paraná, Brasil. E-mail: solperin01@gmail.com. https://orcid.org/0000-0002-4033-270X.

** Universidade Estadual de Maringá. Maringá, Paraná, Brasil. E-mail: teleoliv@gmail.com. https://orcid.org/0000-0001-5349-1059. 


\begin{abstract}
This work analyzes the pedagogy of Ramon Llull (1232-1316) through his work Doctrina Pueril, written for his son, Domingos, around the year 1275-76. We will study some chapters of this work, which deal with the education of children and the rules established by Llull as essential for human formation. According to the author, human development is not something that is acquired naturally, because of the demand for teachings, models and examples that children learn and follow from an early age. In this way, we will focus the analysis on the educational principles that Llull taught his son, concerning the importance of faith; the apprehension and use of the sciences by means of rationality; the feelings that exalt and depreciate the human being. To this end, other intellectuals of the Middle Ages, such as Hugo de San Vitor (1096-1141), Bonaventure of Bagnoregio (1221-1274), among others. In this sense, understanding that education is a timeless requirement, the study have as methodological assumption the History of Long Duration, by which we can, according to Marc Bloch (1886-1944), to understand man as a 'permanent fund' of any historical moment.
\end{abstract}

Keywords: Ramon Llull. Intellectuals. Teaching/Pedagogy.

\title{
Introdução
}

Analisar a obra de um autor, ainda mais um clássico, requer um entendimento do seu contexto e da sua obra. Isso se deve ao fato dela ir muito além da sua época e servir de estímulo para reflexões acerca de temas que abordou próprias para outros momentos históricos. Esse é o 'destino' de obras como Doctrina Pueril, de Ramon Llull (1232-1316). Ela não se esgota no estudo de como esse autor concebia a formação do homem para a sociedade da sua época, final do século XIII e início do XIV. Ela nos suscita questões para se pensar a educação da criança que seria adequada a outros períodos históricos. Para além das particularidades de uma educação própria de uma época, devemos levar em conta aquilo que poderia ser considerado os aspectos mais gerais de uma educação ou formação da pessoa independentemente do momento histórico. Em outras palavras, a questão que informa nosso estudo é se haveria um modo de conceber a educação que estivesse além dos "constrangimentos históricos" e fosse, por isso, a base a partir da qual se poderia pensar questões relacionadas à formação do homem em dada época histórica. Sabemos que a sociedade procura educar seus membros dentro dos valores e reclamos que lhe são válidos. Mas, 
além disso, haveria algo que seria comum à educação de todas ou, ao menos, quase todas as formas sociais? Essa é a indagação que percorre este texto.

Uma simples pesquisa sobre as obras desse autor, sobre os estudos relativos a ele, nas mais diferentes épocas e nos mais distintos países, a existência de institutos e associações destinadas à análise de divulgação dos seus trabalhos indica se tratar de um autor que tem muito a dizer a nós, que vivemos cerca de setecentos anos após sua morte.

Pouco se sabe sobre Llull até a sua vida adulta. De acordo com Sebastián Garcías Palou (1989), na obra autobiográfica de Llull, Vita Coetânea (1311), nada consta sobre a sua instrução "De su formación científica superior el redactor de la 'Vita Coetanea' no escribió uma sóla línea" (p. 16).

Llull foi casado com Blanca Picany, teve dois filhos e, aos 32 anos, se converteu ao cristianismo. Segundo Alexander Fidora s/d, p. 3), Llull, escreveu mais de 250 obras em catalão, latim e árabe "[...] os escritos que nos foram legados do grande estudioso maiorquino superam em sua totalidade o número de 250 obras que somam cerca de 27.000 páginas." Prossegue esse autor observando que "Deve considerar-se Raimundo Lúlio, dessa forma, o maior polígrafo medieval depois de São Alberto Magno".

A nosso ver, Llull representou, para o século XIII, a figura de um pensador que, abrangendo diferentes culturas; tinha o intuito de que os seus ensinamentos pudessem alcançar os mais diferentes povos. Além de poliglota, teve a sensibilidade didática de escrever de forma mais sintética para que todos pudessem compreender a essência do seu pensamento.

[...] realista para reparar nas limitações práticas de seus leitores que não iriam examinar todas as suas obras -. Atento, pois, a estas limitações e para evitar que a posteridade o reduzisse a seu bel-prazer a um Lúlio em formato de livro de bolso, ele mesmo, em 1308, logo antes de acabar o Ars generalis ultima, sua obra-prima, compõe a Ars brevis que, como disse, foi escrito a modo de imagem da Ars generalis ultima (FIDORA, s/d p. 3-4).

Llull compreendia as necessidades e as exigências da sua época, que giravam, principalmente, em torno da reeducação, com o objetivo de que as questões comerciais e citadinas não dispersassem a crença divina. Le Goff (2007) indica a importância dos pensadores-religiosos na história do século XIII-XIV. Segundo ele, foi um momento em que as cidades, o comércio, a procura do saber e a difusão de novos preceitos religiosos na vida urbana tiveram grande contribuição no desenvolvimento da Europa. Ele os explica a partir de quatro campos: 
O primeiro é o do crescimento urbano. [...] no século XIII se impõe uma Europa urbana [...] É ai que acontecerão as principais misturas de população, que se afirmarão novas instituições, que aparecerão novos centros econômicos e intelectuais. O segundo êxito é o da renovação do comércio e da promoção dos mercadores [...]. O terceiro êxito é o do saber. Atinge um número crescente de cristãos pela criação de escolas urbanas, o que corresponde ao que chamaríamos de ensino primário e secundário [...] Mas se notará, sobretudo, para a nossa finalidade, a criação e o sucesso rápido de centros que diríamos de ensino superior, as universidades. [...] Finalmente, o quarto acontecimento, que sustenta e alimenta os três outros. Trata-se da criação e extraordinária difusão, em cerca de trinta anos, de novos religiosos que residem na cidade e são ativos sobretudo no meio urbano [...] (LE GOFF, 2007, p. 143) ${ }^{1}$.

Nesse contexto, Llull escreveu a obra Doctrina Pueril, priorizando a educação da criança, de um modo geral, pela via de ensinar aos pais como deveria ser a educação dos filhos. Sem dúvida, se trata de uma obra que nos permite perceber a importância que o autor dava à educação da criança, afirmando que a educação se inicia da base, tanto da família quanto dos bons ensinamentos moral e ético, que as crianças apreendem por meio de ensinamentos e exemplos.

Doctrina Pueril foi traduzida do catalão medieval para a língua portuguesa pela equipe do grupo de pesquisas medievais da Universidade Federal do Espírito Santo, coordenado pelo professor Ricardo da Costa. Com a tradução, essa obra foi estudada e veiculada no Brasil por meio de artigos publicados em periódicos, capítulos de livro e apresentação de artigos em eventos, dentre os quais podemos citar: Reordenando o conhecimento: a educação na Idade Média e o conceito de Ciência expresso na obra Doutrina para Crianças (c. 12741276) de Ramon Llull, artigo apresentado por Ricardo da Costa na II Jornada de estudos Antigos e Medievais, Maringá, 2002; A Morte e as Representações do Além na Doutrina para crianças (c.1275) de Ramon Llull - Ricardo da

1 Para maior aprofundamento acerca da relevância destes dois últimos aspectos, a Universidade e os mendicantes na cidade, Oliveira (2009, p. 691) menciona que: “É, pois, neste contexto citadino de mudanças mentais e estruturais profundas que assistimos ao surgimento de um dos maiores movimentos religiosos e intelectuais da Idade Média, as Ordens Mendicantes. Estas ordens surgiram em oposição às atitudes da Igreja e de seus representantes que se voltavam cada vez mais para a riqueza e o luxo terreno, em detrimento dos consagrados valores cristãos. Quatro ordens surgem no século XIII: os Franciscanos, os Dominicanos, os Carmelitas e os Agostinianos, mas as duas primeiras foram as que mais se destacaram. Este movimento tem como características principais o voto de pobreza e a pregação/evangelização. Todavia, especialmente os dominicanos se dedicam, com afinco, aos estudos e as investigações científicas, aliás, dois dos principais mestres da Universidade parisiense, Boaventura de Bagnoregio e Tomás de Aquino saem delas". 
Costa, publicado no livro 'A arte de morrer - visões plurais', em 2010; O príncipe luliano como resposta à questão da dualidade ética e política na ação do governante a partir da obra doutrina para crianças (c. 1274-1276) de Ramon Llull (1232-1316), publicado no "I Congresso Internacional de Filosofia, Moral e Política", em 2009, na cidade de Pelotas, pelo autor Diego Atahualpa Farias; $A$ primeira educação da criança na Península Ibérica medieval: recomendações e instruções de Ramon Llull e IBN Khakdun (1274-1378), Camila Tatiane de Souza, apresentou o trabalho no XI Congresso Nacional de Educação - Educere, em Curitiba - 2013; A educação do infante ao príncipe nas obras de Ramon Llull: caminhos da formação pedagógico-cristã no século XIII, Fabiana de Oliveira, Revista Signum, 2016. Por fim, não poderia deixar de mencionar a tese de doutorado intitulada O Livro da Ordem de Cavalaria, de Raimundo Lúlio: uma proposta de educação social pautada no modelo de conduta virtuosa, de Paula Carolina Teixeira Marroni (2015), foi desenvolvida junto ao Grupo de Pesquisa Transformações Sociais e Educação nas épocas Antiga e Medieval, do qual as autoras deste artigo participam.

Não encontramos outros textos específicos sobre a/ referentes, especificamente, à obra, porém, dentre vários trabalhos realizados no Brasil sobre Ramon Llull, Doctrina Pueril é referenciada em muitos deles.

Antecipadamente, ressaltamos que não faremos comparações entre passado e presente, porém, consideramos que algumas correspondências podem ser feitas entre diferentes momentos pelo fato de que, tanto no período de Llull, como em qualquer outro, quando falamos de educação e de formação humana, estamos analisando o homem na sua mais ampla dimensão, entendendo que, independentemente da época tratada, o homem é o 'fio condutor' da história, como afirma Marc Bloch (1886-1944) em Apologia da História ou oficio do historiador: "Convimos, todavia, em que existe na natureza humana e nas sociedades humanas um fundo permanente. Se assim não fosse, os próprios vocábulos de "homem" e de "sociedade" não significariam coisa nenhuma" (BLOCH, 1967, p. 42).

Desse modo, consideramos essencial levar em conta que o estudo de um autor clássico nos possibilita encarar a sociedade na qual estamos inseridos com um olhar mais crítico e aprimorado no que diz respeito às relações sociais. Clássico, portanto, é aquele autor que nos permite, por meio das suas obras, indagar se as questões apresentadas por ele se vinculam somente ao passado ou se podem, ainda que de forma mediata e indireta, ser vinculada ao presente. O clássico, a nosso ver, extrapola seu tempo e nos permite refletir sobre outra época, como a nossa. Com isso induz o leitor a refletir sobre dúvidas e afirmações que perpassam qualquer período, favorecendo o leitor a pensar sobre suas próprias ações e comportamentos. De acordo com Ítalo Calvino (1923-1985). “O clássico 
não necessariamente nos ensina algo que não sabíamos; às vezes descobrimos nele algo que sempre soubéramos [...] mas desconhecíamos que ele o dissera primeiro [...]. E mesmo esta é uma surpresa que dá muita satisfação, como sempre dá a descoberta de uma origem, de uma relação, de uma pertinência (CALVINO, 1993, p. 12)

Para Calvino, clássico é o autor que nos leva a pensar em questões explícitas na nossa realidade, mas que não as tínhamos percebido ou compreendido da forma como deveriam. Llull, quando analisado dessa perspectiva, pode ser considerado um autor clássico. Apesar dos séculos que nos distanciam, as suas análises referentes à sociedade, à educação e à criança da sua época nos permitem entender que o desenvolvimento da criança e do futuro cidadão está interligado pela educação transmitida pelos pais e pelo conhecimento científico que a criança apreende no decorrer da sua formação. Logo, estamos tratando de questões do passado, mas que suscitam reflexões sobre o nosso presente. Como afirma Braudel (1902-1985), não pretendemos decompor “[...] o tempo passado e escolhe[r] as suas realidades cronológicas segundo preferências e exclusões mais ou menos conscientes" (1990, p.9), mas sim, entender que "Se a história está obrigada, por natureza, a prestar uma atenção privilegiada à duração, a todos os movimentos em que esta se pode decompor, a longa duração parece-nos. neste leque, a linha mais útil para uma observação e uma reflexão comuns às ciências sociais" (BRAUDEL, 1990, p. 37).

Assim, este estudo analisa a proposta pedagógica de Llull por meio da sua obra Doctrina Pueril (Doutrina para crianças), escrita para seu filho, Domingos, por volta do ano de 1275-76, com o objetivo expor a necessidade da formação humana desde criança. Nosso estudo considera de três aspectos destacados pelo autor como essenciais à educação, que são: fé, conhecimento e movimento racional. Estes norteiam e estão implícitos em todos os capítulos da obra, que está subdividida da seguinte forma: Prólogo; Dos Treze Artigos; Dos Dez Mandamentos; Dos Sete Sacramentos da Santa Igreja; Dos Sete Dons que o Espírito Santo dá; Das Oito Bem-aventuranças; Dos Sete Gozos de Nossa Senhora; Das Sete Virtudes que são os Caminhos da Salvação; Dos Sete Pecados Mortais pelos quais o Homem vai à Danação Perdurável; Das Três Leis; Das Sete Artes; Das Matérias Diversas. Cada parte, por seu turno, apresenta diversos capítulos.

A obra de Llull explicita a preocupação social do autor em relação ao modo como os pais, em geral, educavam os filhos. Para ele, era preciso que os pais tivessem, desde cedo, uma atenção especial para com a formação dos filhos. Na proposta lluliana, os pais necessitavam de um planejamento para a formação dos filhos de maneira que, quando adultos, agissem com os sentimentos de honra, respeito e lealdade perante a sociedade. 


\section{Dialogando com o filho}

Llull escreve a obra como se estivesse 'dialogando' com o filho, construindo argumentos para lhe evidenciar que a sociedade em que viviam, do seu ponto de vista, facilitava a corrupção por meio do mau comportamento que se expressava nos 'sete pecados mortais', analisados por ele como: Gula; Luxúria; Avareza; Acídia; Soberba; Inveja; Ira.

Esses são comportamentos consagrados como pecados capitais na Idade Média e, no século XIII, época de Llull, eles passaram a ser duramente combatidos pelos intelectuais da Igreja e pelos monges, pois, na medida em que a vida passa a ser citadina, a convivência entre os homens se torna mais complexa e próxima. As mudanças de vida que vinham ocorrendo há séculos, cada vez mais se instauravam na vida das pessoas e, com essas transformações, eram desencadeadas diversas maneiras de pensar, de comportamento, que resultavam em atritos sociais. De certo modo, eram uma novidade, já que, quando a vida era basicamente rural, esses comportamentos, ainda que enraizados nas pessoas, não afetavam a sociedade em geral.

Desse modo, Llull vive e participa de uma sociedade que atravessava mudanças. Ele entende que alguns sentimentos estavam sendo desvirtuados (sete virtudes - serão citadas abaixo), dando espaço para a permanência de comportamentos (sete pecados mortais - citados acima) que poderiam proporcionar uma desorganização social. Por isso, o autor, por meio da obra Doctrina Pueril, procura estabelecer um direcionamento aos pais. Mostra que a responsabilidade de educar os filhos deveria ter como princípio a formação do homem para a vida em comum. Assim, a educação das crianças deveria estar fundamentada nas sete virtudes, consideradas como os caminhos da salvação. Fé, esperança e caridade. Estas eram as virtudes teologais; justiça, prudência, fortaleza e temperança, por sua vez, eram as virtudes cardiais, apresentadas como essenciais para a vida na cidade. Essas sete virtudes conduziriam os homens ${ }^{2}$ à salvação, mas, acima de tudo, mantinham as relações entre as pessoas dentro de um princípio de harmonia cristã.

2 Segundo Llull, a formação dos homens como condição do ser humano (corpo e alma) deveria ser iniciada desde criança por meio da educação dada pelos pais "[...] ao homem deve ser muito caro seu filho. Por isso, o homem não deve ser negligente com seu filho para que veja e perceba em qual educação ele se habitua e se inclina, pois através da educação do corpo, a educação da alma é habituada, e através da educação da alma, a educação do corpo também é acostumada (LLULL, 1961, p.79). 
É importante destacar que Llull aborda essas mudanças e critica o comportamento dos homens, mas não critica o comércio e o desenvolvimento da sociedade, fundamentos dessas mudanças. Sua crítica se volta para a educação do burguês e a forma como ele estava se comportando e educando seus filhos para a sociedade. Salienta-se que o autor não demonstra nostalgia pela antiga forma de sociedade ou de homem. Ele mostra que todos querem ser como o burguês, mas que o burguês estava se consumindo, isto é, conseguiu acumular riquezas, mas não sabia guardar; pensava no corpo e não educava a alma "Quase todos os homens que estão nos ofícios [...] desejam estar no estamento de burguês e desejam que seus filhos sejam burgueses, mas não há em todo o mundo nenhum ofício tão danoso e que dure tão pouco" (LULL, 1961, p. 66).

Para tanto, Llull apresenta a sequência do seu pensamento. No Prólogo, o autor revela o princípio de toda educação, mostrando ao filho quais seriam os objetivos de Deus perante o homem na Terra. Ele afirma: "Dios quiere que nos ocupemos y esforzemos em servirle [...] Así pues, ya al comienzo debe ensenar a su hijo las cosas más generales del mundo, para que de ellas sepa descender a las particulares" (LULL, 1961, p. 266). A primeira questão a ser tratada para a educação dos filhos, segundo ele, era a fé. A crença de que Deus criou tudo e que teria o domínio sobre todas as coisas, potencialmente direcionaria as ações dos homens e estes agiriam com sentimentos. Era vital, portanto, que, desde cedo, a criança estabelecesse uma relação íntima com o poder divino e os pais deveriam possibilitar que seus filhos crescessem agindo de acordo com os mandamentos de Deus. Logo, se as crianças aprendessem a agir segundo as premissas das virtudes, quando adulto e vivendo em comunidade, estariam habituados a serem virtuosos.

Nos cinco primeiros capítulos, o seu empenho é mostrar ao filho que a fé supera qualquer coisa e que sem ela, como a vida era uma passagem pela Terra, tornar-se-ia insignificante e sem nenhum objetivo concreto. Dessa forma, era preciso conhecer a sabedoria de Deus e entender que a consciência sobre Ele não se faz sem estudar os conhecimentos que havia deixado aos homens. Nesse caso, Llull afirma que a questão principal se relaciona com o desenvolvimento do intelecto, haja vista que só o uso do intelecto possibilitaria criar habilidades de reflexão e de discernimento suficientes para alcançar a sabedoria (sapiência) dada por Deus: "Filho, a sabedoria que o Espírito Santo dá é diferente da sabedoria deste mundo, pois com a sabedoria deste mundo muitos homens que são chamados de sábios cometem faltas e pecados, mas com a sabedoria que o Espírito Santo dá, ninguém pode cometer falta ou pecado" (LULL, 1961, p. 26). Como monge cristão, Llull defendia a ideia de que Deus criou o homem e lhe deu o intelecto. Entretanto, nem todos conseguem desenvolver a inteligência a ponto de chegar à sapiência. Isso não quer dizer que, para o autor, os homens 
não possuíam o intelecto, mas que eram poucos os que alcançariam a sabedoria divina, ou seja, agiriam com a finalidade de atingir o bem comum.

Llull admitia os erros humanos e possíveis de serem aceitos, mas, alguns erros não eram admissíveis, no sentido de que eram prejudiciais ao coletivo. Logo, o conhecimento, segundo ele, era imprescindível para que os homens pudessem discernir entre o comportamento correto e incorreto: "Filho, o entendimento é o poder da alma que entende o bem e o mal, e entende a diferença, a concordância e a contrariedade nas criaturas, e pelo entendimento, o homem conhece as coisas que são verdades e as coisas que são falsas" (LULL, 1961, p. 27).

Para o autor, o conhecimento pode ser adquirido de duas formas, ambas pela via das ciências, porém, com diferenças de entendimento do mundo: uma, é aquela que o homem conhece somente pela razão e faz uso desse conhecimento com vistas às suas vontades particulares; a outra, é a que vincula fé e razão, dada pelo Espírito Santo e que faz o homem agir pelo elevado conhecimento: "Muitos são os homens que amam ter ciência mas não podem tê-la, porque não têm o entendimento claro, e muitos homens recebem a ciência de um elevado entendimento" (LULL, 1961, p. 27).

Llull e outros autores da sua época, como Boaventura de Bagnoregio (1221-1274), consideravam o uso da razão como uma questão essencial para o desenvolvimento do conhecimento, porém, de acordo com eles, mesmo a razão vinculada à fé, o uso da razão deveria sempre ser subordinado aos ensinamentos divinos. Segundo Boaventura:

Toda a dádiva preciosa e todo dom perfeito vem de cima, descendo do Pai das luzes, diz São Tiago, no capítulo primeiro. [...] Embora toda a iluminação do conhecimento seja interna, podemos, contudo, introduzir uma distinção de razão e dizer que há uma luz exterior, a luz da arte mecânica; uma luz inferior, a luz do conhecimento sensitivo; uma luz interior, a luz do conhecimento filosófico; e uma luz superior, a luz da graça da Sagrada Escritura. A primeira luz ilumina no que se refere às figuras ou objetos artificiais; a segunda, no que se refere à forma natural; a terceira, no que se refere à verdade intelectual; e a quarta e a última, no que se refere à verdade da salvação (BOAVENTURA, 1985, p. 207).

Nesse caso, para Boaventura, o conhecimento, quando adquirido pela sequência das luzes, possibilitaria aos homens agirem segundo as virtudes. Assim como Boaventura, para Llull, a fé era a base de todo o conhecimento para se chegar ao comportamento virtuoso. Ele procurava ensinar ao filho que a razão possibilitava ao homem conhecer e crer naquilo que não conseguia ver 
com olhos do corpo, pois, quando o intelecto é desenvolvido pela luz da graça, o conhecimento propicia entender a criação de muitas coisas que compõem o mundo e, também, que outras não eram possíveis de serem explicadas pela via racional. Nesse sentido, ele assevera:

\begin{abstract}
Assim como a luz ilumina teus olhos corporais, pela luz da graça, vês o que crês do celestial Deus na glória e de Suas obras. E como a luz do entendimento não basta para entender tudo o que é necessário ao homem para crer em Deus e em Suas obras, Deus Ilumina com a luz da graça a alma do homem para crer nas coisas invisíveis. Amável filho, pela luz da fé o entendimento se exalta para entender, pois assim como a luz vai à frente para mostrar os caminhos, a fé vai à frente do entendimento. Assim, se desejas ter um entendimento sutil, não sejas incrédulo e crê, para que possas elevar teu entendimento tão alto que entendas o que a fé ilumina (LULL, 1961, p. 41).
\end{abstract}

Desse modo, para LLul, essa obra doutrinal era uma espécie de 'manual' de instrução para educar os filhos. Além de ensinar o seu filho, se dirigia aos pais para que as lessem. $\mathrm{O}$ autor, inclusive, subdivide os capítulos em vários pequenos parágrafos que sintetizavam aquilo que pretendia colocar em evidência. Consideramos que essa subdivisão favorecia o leitor a não ter dificuldades de entendimento.

A propósito, um dos capítulos é voltado especificamente à maneira como se deve educar o filho. Esse capítulo resume todos os pontos que os pais deveriam, de maneira geral, dedicar à educação dos filhos. $\mathrm{O}$ autor inicia os seus ensinamentos sobre a educação das crianças revelando aos pais que "A educação é acostumar o outro ao hábito mais próprio à obra natural. Pois assim como a natureza segue seu corpo e não se desvia de sua obra, as crianças, no princípio, se acostumam à boa educação ao a má" (LULL, 1961, p.78).

Para o autor, é essencial que a educação da criança tenha início desde muito cedo, pois os bons ou maus comportamentos vão depender de como a criança é acostumada pelos pais. Entendendo que, na família, as pessoas se respeitando e fazendo uso de bons comportamentos, a criança irá se adaptar ao que é 'natural' no meio em que vive. Se pai e/ou a mãe agirem sem virtudes, o filho, provavelmente, fará o mesmo, considerando que tais ações são naturais entre os familiares e que, consequentemente, todos podem agir do mesmo modo.

Precedido desse argumento, Lull afirma que a educação se dá pelo corpo e pela alma, pois, nessas duas partes do todo humano, corpo e alma, a aprendizagem ocorre pelos hábitos e pelos ensinamentos dos pais. Em relação à educação corpórea, os ensinamentos dar-se-ão pelos sentidos: ver; ouvir; cheirar; degus- 
tar; apalpar. A educação da alma, por seu turno, deveria ser realizada por meio dos sentidos invisíveis que, potencialmente, pertencem ao intelecto: memória, entendimento e vontade.

As duas formas de educação estão interligadas. Para o autor, o homem é corpo e alma, logo, não é possível educar o corpo sem educar a alma e vice-versa. Assim, para Llull, a educação é única nas duas formas: se educa para corpo e a alma apreende; se educa para a alma e o corpo apreende, uma vez que o homem é um todo indivisível.

A tentação entra na alma através da visão corporal. Por isso, o homem deve educar seu filho a ver coisas que não o acostumam a malvados pensamentos, nem o façam desejar belas vestimentas, onde o orgulho, a inveja e as despesas são engendradas, e ao mesmo tempo das outras coisas semelhantes a essas.

$[\ldots]$

Acostumar seu filho a ouvir vaidades, palavras feias, romances e canções e as outras coisas que dão movimento da luxúria é veneno e peçonha na lembrança, no entendimento e na vontade de teu filho. E tal veneno e peçonha gastam e deterioram os bens que lhe deixas, e aprisionam a sua alma no fogo perdurável. Assim, para mortificar tal veneno são necessárias palavras e livros que falem de Deus e do menosprezo do mundo, antes que o veneno e a peçonha se multipliquem em seu hábito (LULL, 1961, p. 79).

Essas são questões que devem estar ausentes do cotidiano da criança, uma vez que são prejudiciais na educação e interferem no seu corpo e na sua alma, pois correspondem a um possível hábito dos pecados mortais, nos quais, quando adulta, se tornam 'naturais' e afetam a sociedade, contribuindo para a permanência de comportamentos distanciados dos ensinamentos de Deus.

Llull procura detalhar quais são as formas de educação pela via do corpo e da alma que, muitas vezes, os pais usam e acabam se distanciando da boa educação das crianças. Para tanto, ele tece explicações de como proceder desde o nascimento da criança, mostrando aos pais que a falta ou o exagero de cuidados contribuem para a má formação do filho.

Ao iniciar os ensinamentos sobre a educação do corpo, Llull principia pela amamentação, referindo-se à necessidade da criança não ingerir outro tipo de alimento senão o leite, até a idade de aceitação e digestão. Explica ainda que, quando a criança passa a comer outras coisas, "[...] não deve lhe dar mais pão pela manhã e nem a merenda, mesmo que peça, pois ela não irá comer o assado, a fruta e as outras coisas no tempo que tiver que comer" (LULL, 1961, p.79). 
Ao tratar da amamentação do bebê e da alimentação dos maiores, o autor se refere à necessidade de controlar a gula desde cedo para a boa saúde da criança e, também, pensando nessa criança quando adulta. Segundo ele, quando o estômago (parte do corpo) é educado desde cedo, ao se tornar adulta, a criança não tenderá a praticar a gula, pois a alma (cérebro) já terá adquirido o hábito de comer moderadamente.

Ainda sobre a educação do corpo, o autor analisa a importância dos pais não colocarem muitas roupas nas crianças, visto que, ao brincarem, elas suam e a roupa impossibilita a transpiração dos poros, podendo prejudicar a saúde. Expõe ainda sobre o cuidado com os cabelos que, quando a criança, têm pústulas, 'doenças respiratórias, internas, nos ossos' os cabelos devem ser raspados para favorecer a higiene da criança.

Para finalizar as instruções sobre o corpo, ele ensina aos pais a não balançarem o cérebro da criança. Segundo ele, os pais têm a mania de balançar o berço para os bebês pararem de chorar, ignorando que o balançar forçado é um movimento contrário ao cérebro da criança. No último parágrafo referente ao corpo, ele critica os pais ricos que cuidam com exagero do filho dizendo:

\begin{abstract}
Saibas, filho, que mais sábia é a natureza em educar as crianças, que as suas mães. E o que a natureza perde nas crianças filhas dos homens ricos, ganha nas crianças filhas dos homens pobres. Por isso, abre teus olhos e vê quais crianças verás mais sãs e belas: os filhos dos ricos homens ou os filhos dos homens pobres? Sabes por que isso acontece? Porque a natureza dá convenientemente aos filhos dos pobres o que necessitam, e aos filhos dos ricos homens não lhes pode dar o que desejaria. Sabes por quê? Porque muitas vestes e muitas comidas lhe impedem (LULL, 1961, p. 80).
\end{abstract}

No contexto de Llull, século XIII, a riqueza conquistada pelo comércio provocava certa forma de ostentação por meio das roupas, dos bens, dos objetos mais caros etc. Com isso, os filhos dos 'ricos' representavam, perante a sociedade, o poder econômico que os pais possuíam. Desse modo, o exagero de cuidados com o filho, dando-lhe muita comida e vestindo-o com muita roupa, para mostrar a riqueza pessoal, era entendido por Llull como uma contradição à natureza. $\mathrm{O}$ excesso de zelo, segundo Llull, era um exagero prejudicial à educação do corpo da criança, tornando-a um adulto sem bons hábitos e, consequentemente, sem o desenvolvimento das virtudes essenciais para a sociedade. Se os pais não conseguiam educar o corpo do filho, não conseguiriam educar a alma. 
Os homens ricos que não obrigam seu filho ou filha a fazerem alguma coisa e lhes deixam ociosos, não fazem seus filhos lembrarem, entenderem e desejarem, pois a ociosidade, o esquecimento, a ignorância e o indesejar se convêm. Assim, filho, os filhos dos ricos homens se tornam mal-educados, preguiçosos, fracos, néscios e iníquos, e destroem o que recebem, pois não têm alma com a qual saibam guardar e se defender dos homens astutos, falsos, traidores e enganadores (LULL, 1961, p.80).

A educação, de acordo com Llull, era o que poderia melhorar a sociedade, porém, a maneira como os homens ricos estavam educando o corpo e a alma dos seus filhos, dificilmente, do seu ponto de vista, ocorreria uma re/organização educacional. Por isso, ele escreve tentando educar, primeiro, os pais, para que esses pudessem educar os seus filhos, entendendo que a criança, quando se torna adulta, com os hábitos já formados, com a educação que criticava, tenderiam a satisfazer o corpo e a não pensar na alma.

A proposta de Llull em educar o pai já adulto é pensando que o pai sempre quer o melhor para o seu filho e, por isso, mesmo já tendo criado determinados hábitos para o corpo, fará um esforço para mudar esses hábitos em prol da educação do filho.

Se a criança não for educada para trabalhar, quando tiver que trabalhar, não terá paciência nem nobreza de coragem para vencer o seu trabalho. E se a criança for educada para falar mal, quando ouvir dizer, terá inveja, acídia e ira, que são pecados mortais. E se a criança for familiarizada e educada com homens vis, fugirá dos bons homens.

$[\ldots]$

Desejas educar bem seu filho? Acostuma sua memória e seu entendimento a cogitarem nobres feitos para que a vontade ame a companhia de bons homens. E desejas educar o entendimento de teu filho para ser exaltado e elevar seu entendimento? Mostra-lhe a ciência divina e natural. E desejas que ele tenha um elevado entendimento para entender sutilmente? Mostra-lhe a Arte de encontrar a verdade e o Livro de definições de principios e de questões. E desejas que teu filho ame muito a Deus? Faz-lhe lembrar e entender a vileza deste mundo e a bondade, a eternidade, o poder, a sabedoria, o amor e as outras virtudes de Deus (LULL, 1961, p. 80).

A justificativa dada por Llull para educar bem o filho era a do 'Movimento Racional', explicado por ele como uma 'cogitação movida para cogitar uma coisa após outra'. O autor menciona os movimentos do cérebro para ativar a 
memória, o conhecimento e a vontade que nada mais seriam do que movimentos da memória que levariam o homem a agir pela racionalidade desenvolvida pela educação trabalhada com a alma. Para esse movimento era preciso o desenvolvimento do intelecto para provocar o uso da memória e, consequentemente, a memória provocar a vontade do homem pela racionalidade educada pela alma.

Logo, educar a alma requeria conhecimento das ciências; posto isso, Llull trata com mais detalhes de como fazer uso dessas ciências. Ele inicia dizendo que a Teologia é a mais nobre de todas, pois ela é fundada na fé, ou seja, é o ensino dos santos que deveria ser o primeiro a ser seguido.

Como Deus deu natureza e propriedade às criaturas para que naturalmente $\mathrm{O}$ signifiquem e $\mathrm{O}$ demonstrem ao entendimento humano, a Teologia convém com a Filosofia, que é a ciência natural que demonstra Deus e Suas obras por razões necessárias. Isso ocorre de tal maneira que se o homem deseja exaltar seu entendimento a Deus, através da Filosofia pode fazê-lo. $[\ldots]$

Fé e razão convém na sentença da Teologia para que, se a fé cair, o homem se ajude com razões necessárias, e se a razão cair no entendimento humano, que o homem se ajude com fé, crendo nas coisas de Deus que o entendimento não pode entender (LULL, 1961, p. 60).

Llull colocava a Teologia como a principal ciência, mas não desconsidera as demais ciências, pois entendia que o homem precisava de um ofício e para o ofício era preciso do conhecimento de todas as ciências. O que ele questionava era quem só aprendia as ciências pela razão e se esquecia da fé como epicentro de todo e qualquer conhecimento.

O homem burguês, para ele, era um exemplo que não conseguiu fazer o movimento racional e desenvolver a memória suficientemente para usar o entendimento e a vontade pela razão educada pela alma. O burguês atinha-se somente à educação do corpo e, consequentemente, não atingia a educação da alma "Nenhum homem vive tão pouco quanto o burguês. Sabes por quê? Porque come demais e suporta pouco o mal. E nenhum homem faz tanto dano aos seus amigos quanto um burguês pobre, e em ninguém está tão ultrajada a pobreza como está no burguês" (LULL, 1961 p. 66). Por isso, Llull queria educar seu filho a conquistar um ofício, mas não assemelhar-se ao modelo de homem burguês do século XIII, pois, como afirmava, "O burguês deriva dos ofícios ditos acima, pois no princípio de sua linhagem esteve em algum ofício e ganhou tanto que seu sucessor tornou-se burguês. Mas sua linhagem declinará no burguês. Saber por quê? Porque o burguês gasta e não ganha, tem filhos e 
cada um deles está ocioso e quer ser burguês, e a riqueza não é suficiente para todos" (LULL, 1961, p. 66).

Desse modo, as artes mecânicas eram a ciência que visava o ofício e que, para Llull, era uma das ciências que seu filho precisava entender para não fazer como os homens burgueses que perdiam seus ofícios de linhagem ao se tornarem somente burgueses ricos, ociosos e sem a devida educação do corpo e da alma para educarem e ensinarem os seus filhos.

Nesse sentido, o estudo das demais ciências seria, de acordo com Llull, o caminho para o conhecimento e discernimento de uma boa educação e a busca de um ofício. As sete Artes Liberais: gramática, lógica, retórica, geometria, aritmética, música, astronomia, quando bem apreendidas e entendidas como submissas à Teologia contribuiriam para a formação do homem e para os bons comportamentos.

Hugo de São Vítor (1096-1141), anterior a Llull, também tratou das Sete Artes Liberais e da necessidade do seu estudo. O mestre Vitorino ensinava ao professor as prioridades que o aluno deveria ter para o conhecimento do Trivium e do Quadrivium, asseverando que:

As artes são aquelas que estão subordinadas à filosofia, isto é, aquelas que têm como conteúdo alguma divisão certa e determinada da filosofia, como é o caso da gramática, da dialética e coisas parecidas. Complementos das artes são aqueles escritos que apenas se relacionam com a filosofia, isto é, que tratam de algum conteúdo fora da filosofia (HUGO DE SÃO VITOR, Didascálicon, Livro III, cap. 4, p. 141) [...] quando, portanto, lidamos com qualquer ciência, mas, sobretudo, quando a ensinamos, tudo deve ser resumido sinteticamente e exposto de maneira a ser facilmente compreendido, devendo bastar uma exposição quanto mais breve e rigorosa possível sobre aquilo que está sendo tratado, para evitar que, ao multiplicarmos as explicações não pertinentes, turbemos o estudante ao invés de edificá-lo. Não deve ser dito tudo aquilo que podemos dizer, para que não seja dito de modo menos provável aquilo que devemos dizer (HUGO DE SÃO VITOR, 2001, p. 145).

Assim, ainda que mais de um século separe São Vitor de Llull, observamos que a preocupação de ambos era, em linhas gerais, a mesma, ou seja, que os homens necessitavam aprender as ciências, sob a égide da Teologia, e que desenvolvessem a inteligência para a aproximação da sabedoria. Hugo de Saint Vitor visava o método de ensinar o aluno, Llull de educar seu filho, mas o objetivo de ambos era o mesmo: formar o homem para a sua sociedade. 
Llull, por exemplo, revela ao filho que as artes são "[...] ordenamento e estabelecimento da finalidade pela qual se deve ter o conhecimento [...]" (LULL, 1961, p. 58), explicando qual era a função de cada ciência para a sua vida e ressaltando a Teologia como a única que era possível falar com Deus. As demais eram ciências que se apreendia e, quando associada à Teologia, se conhecia Deus como perfeição.

Por meio do conhecimento e da educação do corpo e da alma, segundo o autor, chegava-se aos costumes que nada mais eram do que "[...] agradáveis à alma. Sabes por quê? Porque entre os bons costumes e a consciência é feita a paz. Por isso, a má educação e a consciência são contrárias" (LULL, 1961, p.81).

\section{Considerações finais}

As reflexões apresentadas por Llull sobre a má educação nos remetem à ideia de que a formação do homem da sua época estava fundamentada em princípios que norteiam as relações sociais e que se estabelecem por meio da educação adquirida desde criança. Llull encaminha o diálogo com o filho mostrando que a responsabilidade de educar o corpo era dos pais e que a boa educação corporal resultaria na educação da alma.

$\mathrm{O}$ autor evidencia que a criança, quando direcionada desde seu nascimento, para uma boa educação, o resultado da sua formação será a de um adulto consciente do seu papel na sociedade, entendendo que seus bons comportamentos resultarão em um bem para o coletivo.

A nosso ver, as explicações que Llull dava ao seu filho sobre como educar a criança confirmam a importância do estudo de autores clássicos, já que nos remetem à reflexões acerca da responsabilidade do nosso papel pessoal e profissional na sociedade em que vivemos.

Os ensinamentos de Llull nos possibilitam entender que, quando tratamos do homem-sociedade, não devemos pensar em passado ou presente, mas nas questões primordiais estão presentes em qualquer período e que sempre são evocadas a estarem atuantes nas relações humanas, quais sejam: educação, sabedoria e o pensamento coletivo que resulte em comportamentos com preceitos morais.

Assim, passado e presente se unem em um conceito de 'longa duração', o qual Braudel (1990, p. 17) explica que, entender o passado "equivale a prestar-se a uma mudança de estilo, de atitude, a uma inversão de pensamento, a uma nova concepção do social." Por conseguinte, ao analisarmos o projeto de educação para crianças do século XIII, escrito por Llull na Doctrina Pueril, acreditamos 
que o nosso papel, enquanto pais e educadores, é refletir sobre o projeto de educação que temos para as crianças do século XXI, posto que a nossa responsabilidade, assim como a de Llull, é com a formação humana.

\section{REFERÊNCIAS}

BLOCH, Marc. Introdução à História. Sintra, Portugal: Publicações Europa-América, 1967. (Coleção Saber)

BRAUDEL, Fernand. História e ciências sociais. Trad. Rui Nazaré. Lisboa: Ed. Presença, 1990.

CALVINO, Ítalo. Por que ler os clássicos. Trad. Nilson Moulin. São Paulo: Cia. das Letras, 1993.

FIDORA, Alexander. Raimundo Lúlio - educador das religiões. Trad. Elie Chaderiavam. Disponível em: <http://www.hottopos.com/mirand15/fidora.htm>. Acesso em: 23 jul. 2018.

LE GOFF. As raizes medievais da Europa. Petrópolis: Vozes, 2007.

LLULL, Ramon. Doctrina Pueril. In: LLULL, Ramon. Antologia de Ramon Llull. Madrid. Dirección General de Relaciones Culturales, 1961.

LLULL, Ramon. Doutrina para crianças (1274-1276). Tradução Ricardo da Costa. Disponível em: <http://www.ricardocosta.com/textos/ramon>. Acesso em: 13 nov. 2017.

OLIVEIRA, Terezinha. Memória e história da educação medieval: uma análise da Autentica Habita e do Estatuto de Sorbonne. Avaliação, Campinas; Sorocaba, SP, v. 14, n. 3 , p. 683-698, nov. 2009. Disponível em: <http://www.scielo.br/pdf/aval/v14n3/a09v14n3. pdf $>$. Acesso em: 22 jul. 2018.

PALOU, Sebastián Garcías. La formación cientifica de Ramon Llull. Mallorca: Ed. Inca, 1989.

HUGO DE SÃO VITOR. Didascálicon: da arte de ler. Tradução: Antonio Marchioni. Petrópolis. RJ: Vozes, 2001.

SÃO BOAVENTURA. Redução das ciências à Teologia. In: SÃO BOAVENTURA. Obras Escolhidas. Org. Luis A. de Boni. Caxias do Sul: Livraria Sulina Editora, 1985.

Texto recebido em 20 de maio de 2018 .

Texto aprovado em 31 de julho de 2018. 